\title{
Mutualism between Klebsiella SGM 81 and Dianthus caryophyllus in modulating root plasticity and rhizospheric bacterial density
}

\author{
Shraddha Gang • Meenu Saraf $(\mathbb{D} \cdot$ Christopher J. Waite • \\ Martin Buck • Jörg Schumacher $\mathbb{D}$
}

Received: 13 June 2017 / Accepted: 22 September 2017 / Published online: 8 November 2017

(C) The Author(s) 2017. This article is an open access publication

\begin{abstract}
Aims Dianthus caryophyllus is a commercially important ornamental flower. Plant growth promoting rhizobacteria are increasingly applied as bio-fertilisers and bio-fortifiers. We studied the effect of a rhizospheric isolate Klebsiella SGM 81 strain to promote $D$. caryophyllus growth under sterile and non-sterile conditions, to colonise its root system endophytically and its impact on the cultivatable microbial community. We identified the auxin indole-3-acetic acid (IAA) production of Klebsiella SGM 81 as major bacterial trait most likely to enhance growth of $D$. caryophyllus.

Methods ipdC dependent IAA production of SGM 81 was quantified using LC-MS/MS and localised proximal to D. caryophyllus roots and correlated to root growth promotion and characteristic morphological changes. SGM 81 cells were localised on and within the plant root using $3 \mathrm{D}$ rendering confocal microscopy
\end{abstract}

Responsible Editor: Michael Luke McCormack

Electronic supplementary material The online version of this article (https://doi.org/10.1007/s11104-017-3440-5) contains supplementary material, which is available to authorized users.

S. Gang $\cdot$ M. Saraf $(\bowtie)$

Department of Microbiology and Biotechnology, School of

Sciences, Gujarat University, Ahmedabad 380009, India

e-mail: sarafmeenu@gmail.com

S. Gang $\cdot$ C. J. Waite $\cdot$ M. Buck $\cdot$ J. Schumacher $(\bowtie)$

Department of Life Science, Faculty of Natural Sciences, Imperial

College, London SW7 2AZ, UK

e-mail: j.schumacher@imperial.ac.uk of $g f p$ expressing SGM 81. Using Salkowski reagent IAA production was quantified and localised proximal to roots in situ. The effect of different bacterial titres on rhizosphere bacterial population was CFU enumerated on nutrient agar. The genome sequence of Klebsiella SGM 81 (accession number PRJEB21197) was determined to validate PGP traits and phylogenic relationships.

Results Inoculation of D. caryophyllus roots with Klebsiella SGM 81 drastically promoted plant growth when grown in agar and soil, concomitant with a burst in root hair formation, suggesting an increase in root auxin activity. We sequenced the Klebsiella SGM 81 genome, identified the presence of a canonical ipdC gene in Klebsiella SGM 81, confirmed bacterial production and secretion of IAA in batch culture using LC-MS/ MS and localised plant dependent IAA production by SGM 81 proximal to roots. We found Klebsiella SGM 81 to be a rhizoplane and endophytic coloniser of D. caryophyllus roots in a dose dependent manner. We found no adverse effects of SGM 81 on the overall rhizospheric microbial population unless supplied to soil in very high titres.

Conclusion Klebsiella SGM 81 effectively improves root traits of $D$. caryophyllus in a dose dependent manner, likely through tryptophan dependent IAA production in the rhizoplane and potentially within the intercellular spaces of root tissue. Under optimal plant growth promoting conditions in non-sterile soil, the high total microbial titre in the rhizosphere supports a mutualistic relationship between Klebsiella SGM 81 and carnation that potentially extends to the wider rhizosphere microbiota. 
Keywords Dianthus caryophyllus $\cdot$ IAA $\cdot$ Klebsiella . Plant inoculation assays $\cdot$ Root plasticity

\author{
Abbreviations \\ Gfp Green florescent protein \\ IAA Indole acetic acid \\ ipdC Indole-3-pyruvate decarboxylase \\ PCR Polymerase chain reaction \\ PGPR Plant growth promoting rhizobacteria
}

\section{Introduction}

Plant growth promoting rhizobacteria (PGPR) are a group of bacteria that are found in close vicinity of plant roots and enhance plant growth and development via a combination of various traits, including nitrogen fixation, phosphate solubilisation, plant hormone production, aminocyclopropane-1-carboxylate deaminase production and biolytic enzyme secretion (Bhattacharyya and Jha 2012; Bhardwaj et al. 2014; de Souza et al. 2015). PGPR can aggressively colonize the root structure and are often responsible for biocontrol against pests and pathogens in addition to plant growth promotion (Weller et al. 2002). Despite the ever increasing use of microbial formulations in order to improve plant growth yields, only a few studies have focused on the impact of microorganisms on ornamental plants, namely the application of Azosprillium brasilense (Zulfitri 2012) and Cyanobacteria (Shanan and Higazy 2009) on Lavandula stoechas and Matthiola incana respectively. Bacteria which colonise the regions in and around plant roots (rhizobacteria) are better able to modify, mobilize and/or solubilize nutrient supplements compared to other free-living organisms found in bulk soils (Hayat et al. 2010) microorganisms Azosprillium brasilense.

The production of the phytohormone indole acetic acid (IAA) by some PGPR is considered to be a direct mechanism by which microorganisms can modulate plant growth (Ali et al. 2009). Bacterial IAA can be produced via both tryptophan-dependant and tryptophan-independent pathways (Patten and Glick 1996). IAA exhibits both positive and negative effects on plant development (Mayak et al. 1999). In this way, although IAA plays an important role in enhancing plant root system development, it can inhibit root growth at extreme high or low concentrations. The effects of PGPR-produced IAA on root morphology and development, in particular with regards to specific IAA and inoculum concentrations, have been described previously (Dobbelaere et al. 1999). Rapid root development, inclusive of both elongation of primary roots and development of lateral and adventitious roots, increases the capacity of seedlings to adhere the soil and to acquire water and nutrients from their environment (Patten and Glick 2002a). In contrast to lateral and adventitious roots, which are induced by high IAA levels, primary root development is induced by generally low concentrations of IAA, typically in the nanomolar to picomolar range (Meuwly and Pilet 1991). It is thought that high IAA levels repress the primary root indirectly due to auxininduced ethylene production (Peck and Kende 1995).

Klebsiella species exhibit plant growth promotion by various direct mechanisms, such as the ability to solubilise phosphate (Ahemad and Khan 2011), produce auxins (El-Khawas and Adachi 1999), fix atmospheric nitrogen (Mahl et al. 1965) and protect against abiotic stresses (Wu et al. 2014). Dianthus caryophyllus, commonly known as carnation, is one of the most economically important species in the Caryophyllaceae family, highly valued as an ornamental flower. It is available in a wide assortment of colours and patterns (Shiragur et al. 2004). In addition to its broad aesthetic appeal, the pharmacological potential of carnation has been extensively explored for anticancer, antiviral and other antimicrobial properties (Chandra et al. 2016). In this study, we show the beneficial effects of a $D$. caryophyllus rhizosphere Klebsiella isolate (SGM 81), identify the bacterial IAA anabolic pathway to promote Dianthus' root growth in a dose dependant manner and link Klebsiella SGM 81 soil densities with plant phenotypes and the soil microbiome as a whole. No study has been reported for association of D. caryophyllus and Klebsiella to the best of our knowledge. We show Klebsiella SGM 81 to be an effective root coloniser of $D$. caryophyllus, both in the rhizoplane and the root interior, and discuss their specific mutualism within the wider rhizosphere ecology.

\section{Materials and methods}

Bacterial strain and culture conditions

Klebsiella SGM 81 was isolated from the rhizosphere of D. caryophyllus from Gujarat, India and was selected for the study considering the highest ability to produce IAA amongst all other isolates. The $16 \mathrm{~S}$ rRNA sequence 
was deposited in gene bank under accession number KU748780. This isolate was grown in Nutrient broth (beef extract 1 g. $\mathrm{L}^{-1}$, yeast extract 2 g. $\mathrm{L}^{-1}$, peptone 5 g. $\mathrm{L}^{-1}$ and sodium chloride 5 g.. $\mathrm{L}^{-1}$ ) for routine cultivation, and was preserved as glycerol stock at $-80{ }^{\circ} \mathrm{C}$ for its maintenance. All the growth chemicals and growth media discussed in the study were procured from Sigma Aldrich, UK and VWR, UK.

Isolation of $i p d C$ gene by PCR

The ipdC gene (indole-3-pyruvate decarboxylase) from Klebsiella SGM 81 was amplified by polymerase chain reaction as described previously (Jha et al. 2012) with the following modifications. Specific primers were designed using ipdC gene data of Klebsiella michiganensis strain M5al (accession number AMPJ00000000) from NCBI with the following primer pair: Forward primer: 5' TGATATCGCGTGGCGTTTGCCTGGTA3' and reverse primer: 5' GCGGATTTTCCCGGCGGTGT TCGTCG 3' (Invitrogen, Thermofisher Scientific, UK). $25 \mu \mathrm{L}$ reaction mixtures comprised: $2.5 \mu \mathrm{L}$ of each primer $(10 \mu \mathrm{M}), 12.5 \mu \mathrm{L}$ master mix (50 units/ $\mathrm{mL}$ of Taq DNA polymerase, $400 \mu \mathrm{M}$ dNTP, $3 \mathrm{mM}$ $\mathrm{MgCl} 2$ ), $7.3 \mu \mathrm{L}$ nuclease free water, and $0.2 \mu \mathrm{L}$ of 10 ng genomic DNA (isolated using Zymo research genomic DNA isolation kit). PCR conditions were: initial denaturation at $95^{\circ}$ for $5 \mathrm{~min}$, followed by 35 cycles of $95^{\circ}$ for $30 \mathrm{~s}$, primer annealing at $60^{\circ}$ for $30 \mathrm{~s}$, extension at $72^{\circ}$ for $2 \mathrm{~min}$. This was followed by final extension at $72^{\circ}$ for $10 \mathrm{~min}$. Purity of the PCR product was assessed by electrophoresis on $0.8 \%$ agarose gel stained with SyBR safe DNA gel stain (Invitrogen, UK). PCR reactions were analysed by agarose gel electrophoresis and band of approximately $1.7 \mathrm{~kb}$ size (Supplementary Fig. 1), DNA gel extracted, sequenced (Genewiz, Essex, UK) and the deduced amino acid analysed (UniProt BLAST).

IAA quantification and visualisation by Salkowski method

IAA production of Klebsiella SGM 81 was induced by supplementing Nutrient broth with $0.05 \%, 0.1 \%$, or $0.15 \%(w / v)$ L-tryptophan and cultures were incubated in the dark on an orbital shaker at $200 \mathrm{rpm}$ and $30{ }^{\circ} \mathrm{C}$. IAA production and secretion was measured in culture supernatants at interval of $24 \mathrm{~h}$ till $96 \mathrm{~h}$ using Salkowski reagent as described previously described by (Jha and
Saraf 2011). Briefly, $1 \mathrm{~mL}$ of culture supernatant was mixed with $1 \mathrm{~mL}$ of Salkowski reagent and incubated in the dark for $30 \mathrm{~min}$. Development of pink colour was measured spectrophotometrically at $536 \mathrm{~nm}$ and IAA quantified using an IAA standard.

For in situ Salkowski staining of IAA in plant growth promoting assays, D. caryophyllus roots seven days after germination were dipped into SGM 81 suspensions of indicated titres, grown on agarose media for an additional two weeks and each root was stained with $400 \mu \mathrm{L}$ Salkowski reagent for $30 \mathrm{~min}$.

\section{Analysis of IAA by LC-MS/MS}

IAA from culture supernatants was extracted as described (Jasim et al. 2013). Briefly, Klebsiella SGM 81 was inoculated into $200 \mathrm{~mL}$ of Nutrient broth supplemented with $0.5 \%$ of L-tryptophan and incubated for 4 days (bacterial density reaching approximately 8.0 $\log 10$ CFU.mL ${ }^{-1}$ ) at $30{ }^{\circ} \mathrm{C}$ at $200 \mathrm{rpm}$. Supernatants, following centrifugation at $5000 \mathrm{rpm}$ for $20 \mathrm{~min}$, were acidified to $\mathrm{pH} 2.5-3.0$ with $1 \mathrm{~N} \mathrm{HCl}$ before IAA was extracted with two volumes of ethyl acetate. IAA in the ethyl acetate phase was vacuum dried in a rotational evaporator at $40^{\circ} \mathrm{C}$ and redissolved in $1 \mathrm{~mL}$ of methanol prior to storage at $-20{ }^{\circ} \mathrm{C}$. Identification of IAA was performed by subjecting the methanol extract to LCMS/MS analysis on an Agilent 1100 LC system and an ABSciex 6500 Qtrap MS. Chromatography was on a Phenomenex Luna C18 column $(100 \mathrm{~mm} \times 2 \mathrm{~mm} x$ $3 \mathrm{um})$. The identity of IAA in the samples was confirmed by Enhanced Product Ion scans. Data acquisition and analysis was performed with Analyst 1.6.1 software (AB Sciex).

Plant experimental designs and conditions

Carnation seeds were obtained from an international seed suppliers Thompson \& Morgan and were surface sterilised following the method of Bent (2006). Hundred seeds were allowed to germinate on Murashige and Skoog basal salt medium with $0.8 \%$ agarose, devoid of plant hormone supplements, until root lengths reached $2 \mathrm{~cm}$. Twelve groups of five germinated plants were split into two sets. Both sets were subjected to each of the six treatments by immersing the root tips into $5 \mathrm{~mL}$ of the following for one hour: $10 \mu \mathrm{M}$ bacterial IAA (T1), $10 \mu \mathrm{M}$ synthetic standard IAA (T2), bacterial suspension with titres of $10^{2}, 10^{5}, 10^{8} \mathrm{CFU} \mathrm{mL}^{-1}$ (T3 
to $\mathrm{T} 5$ respectively), or sterile distilled water (TC). Treatments T1-T5 and TC will be used in all further description. The schematic presentation of experimental steps for plant study is also shown in Supplementary Fig. 2

Plant growth experiments on agar

Germinated plants belonging to one set with all six treatments were transferred to MS agar medium devoid of IAA and sucrose in square petri plates $(120 \mathrm{~mm} \times 120 \mathrm{~mm} \times 15 \mathrm{~mm})$. The plates were kept at $25^{\circ} \mathrm{C}$ in $14 \mathrm{~h}$ light and $10 \mathrm{~h}$ dark cycles in a plant culture room. Each plate carried 5 germinated seeds. Root architectures were observed after 21 days. Effect of Klebsiella SGM 81 was also observed on root length of model plant Arabidopsis thaliana col.-0 to validate its effect as root growth promoting agent.

\section{Soil experiments}

For soil experiments, non-sterile soil was used. Compost soil (Levington F2 $+\mathrm{Z}$ seed and modular soil) was mixed with perlite (Levington soil and perlite) for good aeration in a $3: 1$ ratio. Soil/perlite mix was then transferred to pots to provide soil beds, and plants belonging to one set with each of six treatments were transferred to soil beds. Plants were uprooted after 21 days.

Study of root architecture

Root architecture was studied in terms of primary root length, number of lateral roots, number of root hair $/ \mathrm{cm}$ of primary root above the root apical meristem part of the root, fresh root weight and dry root weight and statistical comparisons were made as described by (Grossman and Rice 2012). The statistical analyses of the data was conducted using three replicates. Level of significance was studied using GraphPad prism 6 tool.

Enumeration of root endophytic and rhizosphere bacterial population

Root endophytes were enumerated using method given by Tsavkelova et al. (2007) with slight modification where Roots were collected and subjected to three-step procedure: a $1 \mathrm{~min}$ wash in $70 \%$ ethanol, followed by a
$1.5 \mathrm{~min}$ wash in $20 \% \mathrm{NaOCl}$, and a final rinse in sterile distilled water 3 times. This was followed by grounding them and serially diluting the crushed extract. The dilutions were then plated on nutrient agar plates and incubated overnight at $30{ }^{\circ} \mathrm{C}$ for colony formation. Rhizosphere bacteria were isolated on agar plates following method given by (Jha et al. 2010) with modification. Soil was collected from within the vicinity of $2 \mathrm{~cm}$ of root along with that adhered on root surface. This soil sample (1 g) was suspended in $9 \mathrm{~mL}$ of sterile normal saline and shaken at $200 \mathrm{rpm}$. Soil was allowed to settle, and the supernatant was serially diluted, plated on $\mathrm{Nu}-$ trient agar plates and incubated overnight at $30^{\circ} \mathrm{C}$.

\section{GFP tagging and transformation}

The plasmid pBBR1MCS4-gfp (5508 bp) was constructed for constitutive expression of green fluorescence protein $(G F P)$ in Klebsiella SGM 81. Briefly, the $g f p$ (mut3b) gene (Cormack et al. 1996), preceded by a synthetic sigma-70 promoter (BBa_J23104) and ribosome binding site (BBa_B0030) sourced from the Registry of Standard Biological Parts (http://parts.igem. org), was cloned into the broad host range vector pBBR1MCS4 (Kovach et al. 1994) as an SphI-SacI restriction fragment. pBBR1MCS4-gfp was transformed by electroporation into Klebsiella SGM 81 for fluorescence visualisation in plant tissue. We found that Klebsiella SGM 81 did not readily transform using standard protocols for Escherichia coli, presumably due to high expression of exo-polysaccharides. Therefore, overnight cultures of Klebsiella SGM 81 were reinoculated in LB broth containing $0.7 \mathrm{mM}$ EDTA and cells harvested when an $\mathrm{OD}_{600}$ of 0.5 was reached. The transformation was then conducted as described previously (Fournet-Fayard et al. 1995). Gene knockout experiments to create mutant of ipdC gene was also done by targeted mutagenesis using red recombinase. Bacterial strain was subjected to transformation using red expressing plasmid pKD46 using method given by (Datsenko and Wanner 2000). However attempt to create knockout failed presumably due to low transformation frequency of Klebsiella SGM 81.

Root colonisation microscopy

Root colonisation by GFP-tagged bacteria was studied after 7 days of inoculation, when roots were collected 
and surface sterilised following method given by (Tsavkelova et al. 2007) with slight modifications as discussed above in enumeration of bacteria section. Roots were subjected to three-step procedure: a $1 \mathrm{~min}$ wash in $70 \%$ ethanol, followed by a $1.5 \mathrm{~min}$ wash in $20 \% \mathrm{NaOCl}$, and a final rinse in sterile distilled water 3 times. Roots were cut into sections of $1 \mathrm{~cm}$ and dipped in $10 \mathrm{mg} \cdot \mathrm{mL}^{-1}$ of propidium iodide to stain the plant root cells. Bacterial colonisation images were acquired with a Zeiss LSM 510 confocal microscope, using a $63 \times$ PlanApochromat 1.40 objective, with a z-step of $0.7 \mu \mathrm{m}$ and a $70 \mathrm{~nm}$ pixel size. Micrographs were prepared with Icy (de Chaumont et al. 2013).

\section{Identification of Klebsiella SGM 81}

Genomic DNA isolation and $16 \mathrm{~s}$ rRNA sequencing of Klebsiella SGM 81 was carried out by Chromous Biotech, Banglore, India. The sequence obtained was submitted to NCBI gene bank and accession number was received. Genome sequencing of Klebsiella SGM 81 was carried out by Microbes NG, Birmingham, UK. The downstream processing of sequenced data was accomplished using several bioinformatics tools. Briefly Genome assembly was carried out using the BugBuilder pipeline (http://www.imperial.ac.uk/bioinformaticsdata-sciencegroup/resources/software/bugbuilder/). Contig sequences were scaffolded against the reference genome sequence of Klebsiella oxytoca strain CAV1374 (CP011636.1) using the mauve scaffolder (Darling et al. 2010), followed by gap closure using Pilon (Walker et al. 2014). The assembled genomes were then annotated using Prokka (Seemann 2014) The presence or absence of genes was determined by carrying out blastp searches $(e=0.01)$ (Camacho et al. 2009) against the predicted proteins from the annotated genome, using homologous genes from Klebsiella SGM 81 sequences. To produce phylogenetic trees, available high quality 16 s RNA sequences were obtained from the RDP database (Cole et al. 2005), and a multiple alignment produced using muscle (Edgar 2004). Ambiguous regions were removed from the alignment with BMGE (Criscuolo and Gribaldo 2010) and a bootstrapped maximum likelihood tree constructed using RaXML (Stamatakis 2014), with a GTRCAT model and 10,000 bootstrap iterations.

\section{Results}

Tryptophan dependent pathway of IAA production of by Klebsiella SGM 81

Klebsiella SGM 81 was isolated from the D. caryophyllus rhizosphere during a screen for PGPR. A 16S rRNA gene sequence analysis indicated that the isolated strain belongs to the Klebsiella genus, and was named SGM 81. We observed the presence of Klebsiella SGM 81 stimulated lateral root hair formation of D. caryophyllus seedlings, in a manner dependent on tryptophan in the growth media (see below). The ipdC gene, coding for indole-3-pyruvate decarboxylase, is generally associated with converting tryptophan into indole-3-acetic acid (IAA) (Persello-Cartieaux et al. 2003), a product which is linked to the stimulation of lateral root growth in a variety of plants (Gravel et al. 2007). We amplified a $1.7 \mathrm{~Kb}$ DNA fragment from genomic Klebsiella SGM 81 DNA using primers specific to the ipdC gene in the model Klebsiella michiganensis strain M5al genome sequence (AMPJ00000000). The identity of the amplified fragment to code for ipdC in Klebsiella SGM 81 was confirmed by DNA sequencing, with the deduced amino acid sequence showing $99.8 \%$ similarity with the predicted protein sequence of Klebsiella sp. NFIX56 (NCBI 1566183) (Supplementary Fig. 3).

Next, we assessed the tryptophan dependent production and secretion of IAA from Klebsiella SGM 81. Batch cultures of Klebsiella SGM 81 were grown in the presence and absence of tryptophan and cell supernatants analysed for IAA using both the methods of Salkowski (Jha and Saraf 2011) and LC-MS/MS (Fig. 1). Using the former we found apparent IAA production increased with increasing tryptophan concentrations (Fig. 1a). No IAA production was found prior to inoculation $(0 \mathrm{~h})$ indicating that Klebsiella SGM 81 cells are responsible for this reaction. We found a maximum yield of IAA after $72 \mathrm{~h}$ with $0.15 \%$ tryptophan $\left(215 \mu \mathrm{g} \cdot \mathrm{mL}^{-1}\right)$, but relatively high yields after $24 \mathrm{~h}$ suggest a high rate of IAA production during the first day. Tryptophan alone had no negative effects on Klebsiella SGM 81 growth, in fact a slight positive growth effect, excluding the possibility that growth differentials could account for different IAA production rates (Supplementary Fig. 4). IAA yields decreased after $96 \mathrm{~h}$, potentially due to stationary phase cells and/or potential nutrient exhaustion. 
Fig. 1 IAA detection and quantification using Salkowski reagent and LC-MS/MS. a shows mean values of three replicates for quantitative estimation of IAA by Salkowski reagent after $0 \mathrm{~h}$ (no inoculation) and 24-96 h (after inoculation). Error bar represent one $\mathrm{SD}(n=3)$. b, $\mathbf{c}$ show LCMS/MS plot of commercial standard control and SGM 81 supernatant sample, showing retention times in upper panel (b) and $\mathrm{m} / \mathrm{z}$ ratios in lower panel (c) a

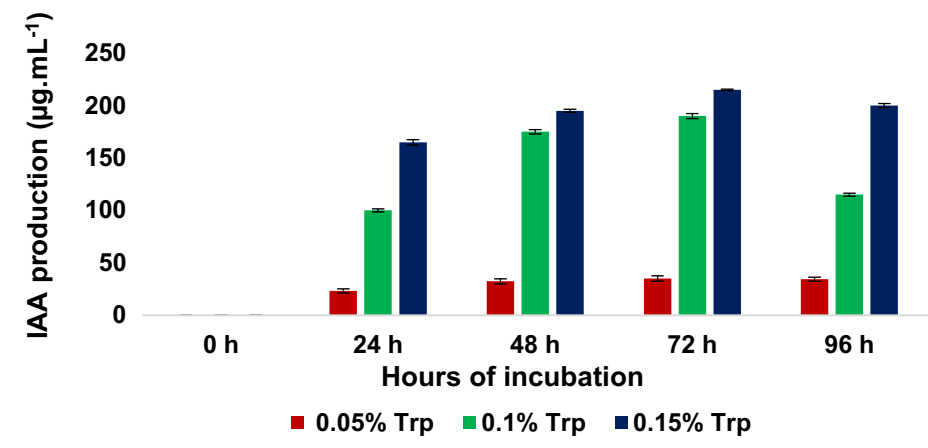

b
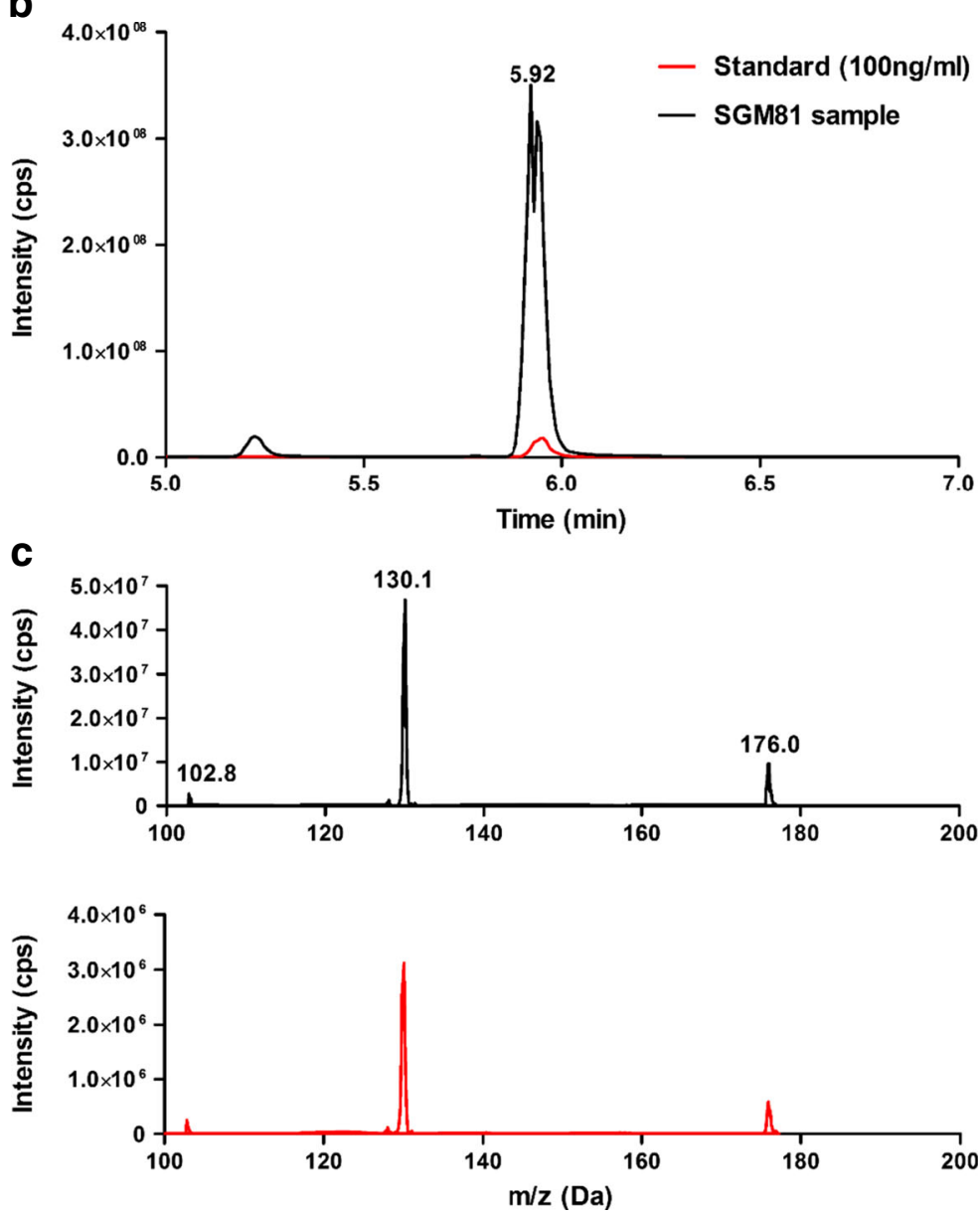

To confirm the molecular identity and assess the purity of IAA produced and secreted by Klebsiella SGM 81, IAA was extracted from cell supernatant and subjected to LC-MS/MS. Overlapping retention times during LC (5.90 $\mathrm{min}$ and $5.92 \mathrm{~min}$ ) and identical $\mathrm{m} / \mathrm{z}$ ratios (130.1) between a commercial IAA standard and sample supernatants showed Klebsiella SGM 81 to produce substantial amounts $\left(960 \mu \mathrm{g}^{*} \mathrm{~mL}^{-1}\right.$ after $72 \mathrm{~h}$ ) of relatively homogeneous IAA when grown in the presence of $0.5 \%$ tryptophan (Fig. 1b). Since we could not detect IAA in the absence of tryptophan, we conclude that ipdC is highly substrate specific and that intracellular tryptophan concentrations of Klebsiella SGM 81 are insufficient to produce detectable amounts of IAA. These results may suggest that IAA is most readily produced in the vicinity of plant roots where tryptophan 
is likely to be present from root exudates, rather than in the bulk soil (Karnwal 2009).

\section{Root growth promotion by Klebsiella SGM 81}

Originally selected isolated for plant growth promoting properties, we investigated Klebsiella SGM 81 plant growth promotion of $D$. caryophyllus in more detail, both in vitro (agarose plates) and in soil with 6 different treatments: $10 \mu \mathrm{M}$ SGM 81 produced IAA (T1), $10 \mu \mathrm{M}$ commercial standard IAA (T2), SGM 81 suspension with titres of $10^{2}, 10^{5}, 10^{8} \mathrm{CFU} \mathrm{mL}^{-1}$ (T3 to T5 respectively), and sterile distilled water (TC). To validate the effect of IAA on D. caryophyllus we supplemented agarose media with a final synthetic IAA $(10 \mu \mathrm{M})$ or the same Klebsiella SGM 81 supernatants used for LC$\mathrm{MS} / \mathrm{MS}$ (for final $10 \mu \mathrm{M}$ IAA). Both treatments induced significant and highly similar phenotypic alterations in root architecture when compared to the water control (Table 1), particularly with respect to increased lateral root development, root hair formation and root fresh weight, with also modest but significant increases in root length and root dry weight. Inoculation of plant roots with different titres of bacterial cells induced similar, but more pronounced root morphological changes (Fig. 2 and Table 1). These results suggest that externally applied IAA causes important root morphological changes in $D$. caryophyllus and imply that IAA production of Klebsiella SGM 81 could largely account for its plant growth promotion properties of $D$. caryophyllus. Differences in root morphological traits were observed when comparing both different inoculum titres and different environments (agarose and soil). The most striking plant phenotypic outcome was the drastically enhanced number of root hairs in plants treated with low (T3) and medium (T4) bacterial cell titres. The T3 treatment has the strongest effect in agarose while the T4 had the strongest impact in soil. Similar results were observed with Arabidopsis thaliana (Fig. 2f, g). The roots of Arabidopsis plants treated with Klebsiella

Table 1 Measurements of root phenotypes in differently treated plants

\begin{tabular}{|c|c|c|c|c|c|c|}
\hline \multirow[t]{2}{*}{ Root architecture } & \multicolumn{5}{|l|}{ Treatments } & \multirow{2}{*}{$\begin{array}{l}\text { Control } \\
\text { TC } \\
\text { Distilled water }\end{array}$} \\
\hline & $\begin{array}{l}\text { T1 } \\
\text { Synthetic IAA }\end{array}$ & $\begin{array}{l}\mathrm{T} 2 \\
\text { Bacterial IAA }\end{array}$ & $\begin{array}{l}\text { T3 } \\
10^{2} \text { CFU.mL } \\
-1\end{array}$ & $\begin{array}{l}\mathrm{T} 4 \\
10^{5} \text { CFU.mL } \\
-1\end{array}$ & $\begin{array}{l}\text { T5 } \\
10^{8} \text { CFU.mL }\end{array}$ & \\
\hline \multicolumn{7}{|c|}{ Primary root length $(\mathrm{cm})$} \\
\hline $\begin{array}{l}\text { MS agar } \\
\text { Soil } \\
p \text { value }\end{array}$ & $\begin{array}{l}4.90 \pm 0.17^{\mathrm{b}} \\
4.90 \pm 0.00^{\mathrm{d}} \\
\mathrm{ns}\end{array}$ & $\begin{array}{l}4.97 \pm 0.29^{\mathrm{b}} \\
5.07 \pm 0.15^{\mathrm{c}} \\
\mathrm{ns}\end{array}$ & $\begin{array}{l}5.03 \pm 0.15^{\mathrm{c}} \\
5.97 \pm 0.21^{\mathrm{d}} \\
<0.0001\end{array}$ & $\begin{array}{l}4.40 \pm 0.17^{\mathrm{a}} \\
9.07 \pm 0.06^{\mathrm{d}} \\
<0.0001\end{array}$ & $\begin{array}{l}1.83 \pm 0.06^{\mathrm{d}} \\
2.03 \pm 0.06^{\mathrm{d}} \\
\mathrm{ns}\end{array}$ & $\begin{array}{l}3.97 \pm 0.12 \\
4.03 \pm 0.06 \\
\text { ns }\end{array}$ \\
\hline \multicolumn{7}{|l|}{ No. of lateral roots } \\
\hline $\begin{array}{l}\text { MS agar } \\
\text { Soil } \\
p \text { value }\end{array}$ & $\begin{array}{l}20.33 \pm 0.58^{\mathrm{d}} \\
18.63 \pm 1.53^{\mathrm{e}} \\
\text { ns }\end{array}$ & $\begin{array}{l}23.67 \pm 0.58^{d} \\
20.67 \pm 0.58^{b} \\
<0.05\end{array}$ & $\begin{array}{l}34.33 \pm 1.53^{\mathrm{d}} \\
21.00 \pm 1.00^{\mathrm{b}} \\
<0.0001\end{array}$ & $\begin{array}{l}18.33 \pm 0.58^{\mathrm{d}} \\
51.00 \pm 2.65^{\mathrm{d}} \\
<0.0001\end{array}$ & $\begin{array}{l}4.67 \pm 1.00^{\mathrm{c}} \\
8.00 \pm 1.00^{\mathrm{b}} \\
<0.05\end{array}$ & $\begin{array}{l}10.67 \pm 0.58 \\
15.33 \pm 1.53 \\
<0.001\end{array}$ \\
\hline \multicolumn{7}{|l|}{ No. of root hairs } \\
\hline $\begin{array}{l}\text { MS agar } \\
\text { Soil } \\
p \text { value }\end{array}$ & $\begin{array}{l}30.67 \pm 0.58^{\mathrm{d}} \\
31.33 \pm 1.53^{\mathrm{d}} \\
\mathrm{ns}\end{array}$ & $\begin{array}{l}30.67 \pm 0.58^{\mathrm{d}} \\
32 \pm 1.00^{\mathrm{d}} \\
\text { ns }\end{array}$ & $\begin{array}{l}85.67 \pm 0.58^{\mathrm{d}} \\
74.33 \pm 0.58^{\mathrm{d}} \\
\mathrm{ns}\end{array}$ & $\begin{array}{l}74.67 \pm 0.58^{\mathrm{d}} \\
117.0 \pm 0.58^{\mathrm{d}} \\
<0.0001\end{array}$ & $\begin{array}{l}0.67 \pm 0.58^{\mathrm{c}} \\
5.00 \pm 0.00^{\mathrm{d}} \\
\mathrm{ns}\end{array}$ & $\begin{array}{l}8.33 \pm 1.15 \\
15.33 \pm 0.58 \\
\text { ns }\end{array}$ \\
\hline \multicolumn{7}{|c|}{ Fresh root weight $(\mathrm{g})$} \\
\hline $\begin{array}{l}\text { MS agar } \\
\text { Soil } \\
p \text { value }\end{array}$ & $\begin{array}{l}0.47 \pm 0.01^{\mathrm{c}} \\
1.03 \pm 0.06^{\mathrm{c}} \\
<0.0001\end{array}$ & $\begin{array}{l}0.47 \pm 0.01^{\mathrm{c}} \\
0.93 \pm 0.03^{\mathrm{d}} \\
<0.0001\end{array}$ & $\begin{array}{l}0.43 \pm 0.02^{\mathrm{b}} \\
1.17 \pm 0.03^{\mathrm{d}} \\
<0.0001\end{array}$ & $\begin{array}{l}0.51 \pm 0.03^{\mathrm{c}} \\
1.49 \pm 0.01^{\mathrm{d}} \\
<0.0001\end{array}$ & $\begin{array}{l}0.1 \pm 0.00^{\mathrm{c}} \\
0.81 \pm 0.01^{\mathrm{d}} \\
<0.0001\end{array}$ & $\begin{array}{l}0.27 \pm 0.03 \\
0.54 \pm 0.00 \\
<0.0001\end{array}$ \\
\hline \multicolumn{7}{|l|}{ Dry root weight(g) } \\
\hline $\begin{array}{l}\text { MS agar } \\
\text { Soil } \\
p \text { value }\end{array}$ & $\begin{array}{l}0.16 \pm 0.002^{\mathrm{e}} \\
0.36 \pm 0.00^{\mathrm{d}} \\
<0.0001\end{array}$ & $\begin{array}{l}0.16 \pm 0.004^{\mathrm{b}} \\
0.31 \pm 0.012^{\mathrm{d}} \\
<0.0001\end{array}$ & $\begin{array}{l}0.21 \pm 0.01^{\mathrm{c}} \\
0.58 \pm 0.025^{\mathrm{d}} \\
<0.0001\end{array}$ & $\begin{array}{l}0.15 \pm 0.00^{\mathrm{e}} \\
0.76 \pm 0.015^{\mathrm{d}} \\
<0.0001\end{array}$ & $\begin{array}{l}0.05 \pm 0.00^{\mathrm{c}} \\
0.41 \pm 0.01^{\mathrm{d}} \\
<0.0001\end{array}$ & $\begin{array}{l}0.14 \pm 0.013 \\
0.17 \pm 0.006 \\
<0.05\end{array}$ \\
\hline
\end{tabular}

Effect of five treatments (Synthetic IAA, bacterial IAA, $10^{2}, 10^{5}, 10^{8}$ CFU.mL ${ }^{-1}$ ) on root architecture. Statistical analysis was done using GraphPad Prism 6 software calculated at $p \leq 0.05$. Data represents mean values of three replicates with standard deviation. Significance of data has been analysed for significant difference in terms of: (i) treatment vs control mentioned through alphabets a $(\leq 0.05), \mathrm{b}(\leq 0.01), \mathrm{c}$ $(\leq 0.001) \mathrm{d}(\leq 0.0001)$ and e (not significant). (ii) MS agar vs Soil mentioned through $p$ values 

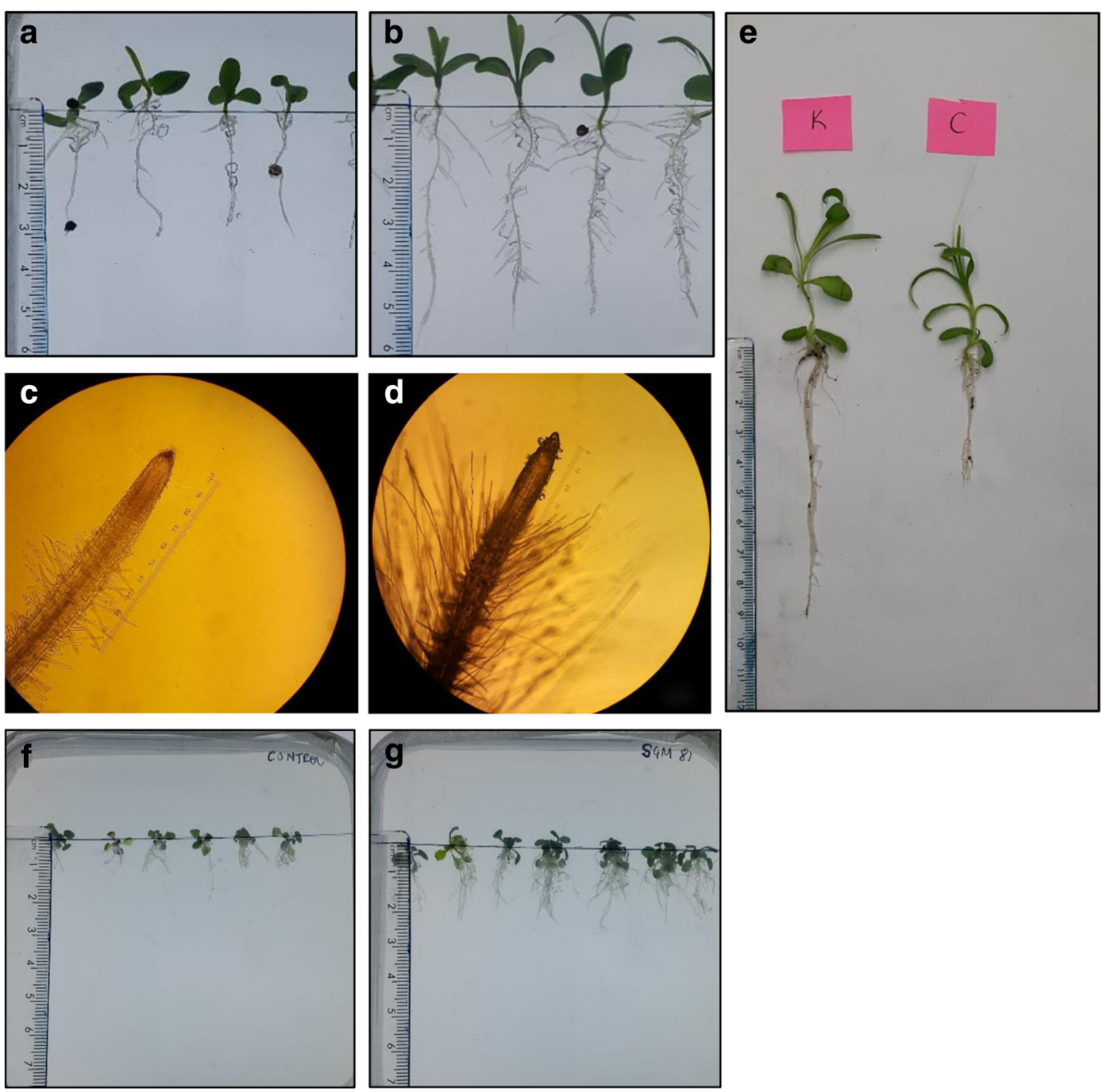

Fig. 2 Root morphology of D. caryophyllus inoculated with Klebsiella SGM 81. Phenotypic difference in root length and number of root hairs in non-inoculated control and treated plants after 21 days. Image shows control plant (a), root length when treated with $10^{2}$ CFU.mL ${ }^{-1}$ Klebsiella (b). Light microscopy images of root hairs in non-inoculated control

SGM 81 were longer and had more lateral roots compared to non-treated roots. However, inoculation of D. caryophyllus with a high titre (T5) of Klebsiella SGM 81 had a very strong negative effect on plant root and plant development in both experimental environments (below).

\section{Klebsiella SGM 81 produces IAA proximal to plant root}

Next we showed that IAA is produced in the SGM 81Dianthus plant growth promotion experiments using (c), and root hairs when treated with $10^{2} \mathrm{CFU} \cdot \mathrm{mL}^{-1}$ Klebsiella SGM 81 (d). Root lengths of non-inoculated control (left) and inoculated $\left(10^{5} \mathrm{CFU} \cdot \mathrm{mL}^{-1}\right)$ D. caryophyllus (right) grown in soil (e). Root length of non-inoculated control and treated plants of Arabidopsis thaliana col.-0 (f, g)

Salkowski reagent on plants. We stained grown plants with $400 \mu \mathrm{L}$ of Salkowski reagent to observe any visible colour change indicating presence of IAA. Figure 3 and Supplementary Fig. 5 show the development of a pinkish colour proximal to roots, indicating the presence of auxin. Maximum colour development was observed in $10^{2}$ CFU. $\mathrm{mL}^{-1}$ (Fig. 3a) and $10^{5}$ CFU. $\mathrm{mL}^{-1}$ inoculated plants (Supplementary Fig. 5a), correlating with best plant root phenotypes (Table 1). The plant roots treated with $10^{8}$ CFU.mL ${ }^{-1}$ (Supplementary Fig. 5b) showed 


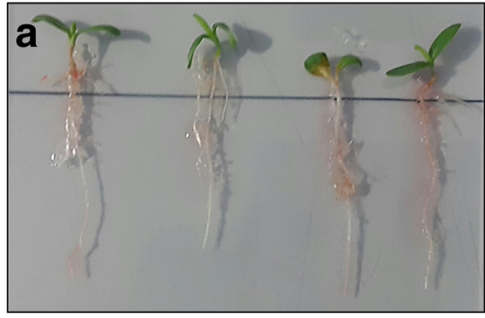

Fig. 3 In situ Salkowski staining on plant roots treated with different Klebsiella SGM 81 and control plants. Visual localisation of IAA using Salkowski reagent on roots of Dianthus caryophyllus treated with: a $10^{2}$ CFU.mL ${ }^{-1}$, b Control plants. The development

adverse plant growth effects and no significant pink colour development. The non-inoculated control plants also did not show pink colour, indicating that the source of the IAA is associated with bacterial colonisation (Fig. 3b). We confirmed on plant free agarose inoculated plates that IAA production by SGM 81 was strictly tryptophan dependent, as it was for batch cultures (Supplementary Fig. 3c,d).

Endophytic colonization of cultivable bacteria in D. caryophyllus

The microbial density and diversity in the rhizosphere is thought to substantially contribute to plant growth and health. The bacterial titre dependent positive and negative impact of Klebsiella SGM 81 to the growth of D. caryophyllus is likely due to its impact on the rhizospheric ecology, comprising microbial composition in non-sterile conditions (soil) and/or plant responses to the addition of Klebsiella SGM 81. We show that Klebsiella SGM 81 colonises D. caryophyllus root tissue (below) and can proliferate endophitically. To evaluate the impact of Klebsiella SGM 81 on the D. caryophyllus rhizosphere ecology, we enumerated over time the densities of bulk soil and endophytic bacterial populations following inoculation with Klebsiella SGM 81. After uprooting and sterilising plants, root extracted cultivable bacteria were counted using colony forming units (CFU) and counts normalised against root fresh weight (Fig. 4). Rhizospheric cultivable bacteria were similarly enumerated per gram weight of soil (Fig. 5). While such methods are semi quantitative at best and do not, for example, enumerate non-cultivatable microbes, we obtained sufficiently consistent enumeration outcomes that may speak to the plant growth outcomes.

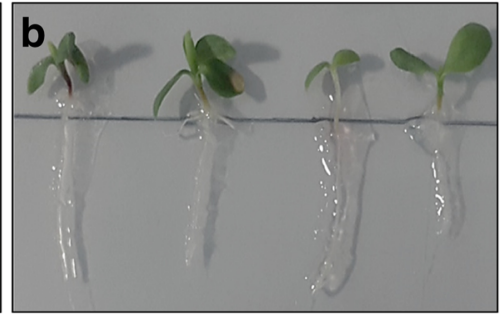

of pinkish red colour proximal to root indicates the presence of auxin. The control plants do not show pink colour upon addition of the reagent which indicates the absence of any exogenous bacterial IAA

The much higher counts of endophytic bacteria after Klebsiella SGM 81 inoculation in sterile MS agar medium (Fig. 4 b-d) compared to water only control (Fig. 4e) suggested that under these conditions Klebsiella SGM 81 sustained the endophytic lifecycle in D. caryophyllus following the inoculation. We attribute the presence of some endophytic bacteria in the water control at $21 \mathrm{DAI}$ either through external contamination or presence of bacteria within the seed (Mastretta et al. 2009). Under all conditions, endophytic populations increased over time, indicating that there is no obvious effective plant response to limit endophytic growth. Endophyte numbers increased with increasing titres, but not linearly. The difference in the population isolated on day 1 from T3 and T4 vs T5 plants is unclear, however, the high endophyte concentration following T5 treatment may be a consequence of damage in root structure due to high bacterial titre, as seen in studies with bacteria Pseudomonas fluorescens SS101 and Paenibacillus polymyxa (Timmusk et al. 2005). In summary, inoculation with increasing Klebsiella SGM 81 titres increases endophytic and soil colonisation, but with highest numbers of endophytes seen under conditions that are deleterious to plant root development (T5), while lower colonisation levels correlated with promoted root growth. No obvious or effective plant defence to limit high endophyte populations was observed although it remains to be shown if the endophytic lifestyle accounts for both beneficial and/or adverse plant growth effects.

Effect of Klebsiella SGM 81 on population of rhizosphere bacteria

We enumerated CFU in the rhizosphere by isolating the soil attached to and around root surface after uprooting. 
Fig. 4 Enumeration of endophytic bacteria. The endophytic growth of cultivable bacteria in $D$. caryophyllus by isolating on Day 0 (a) and at DAI $1,15,21$ from plants treated with $10^{2}$ CFU.mL ${ }^{-1}(\mathbf{b})$, $10^{5}$ CFU.mL ${ }^{-1}$ (c), $10^{8}$ CFU.mL ${ }^{-1}$ (d) and control plants (e). Error bars represent one standard deviation from the mean $(\mathrm{n}=3)$

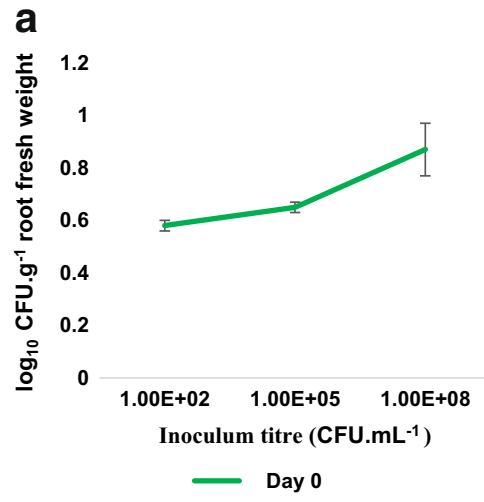

b
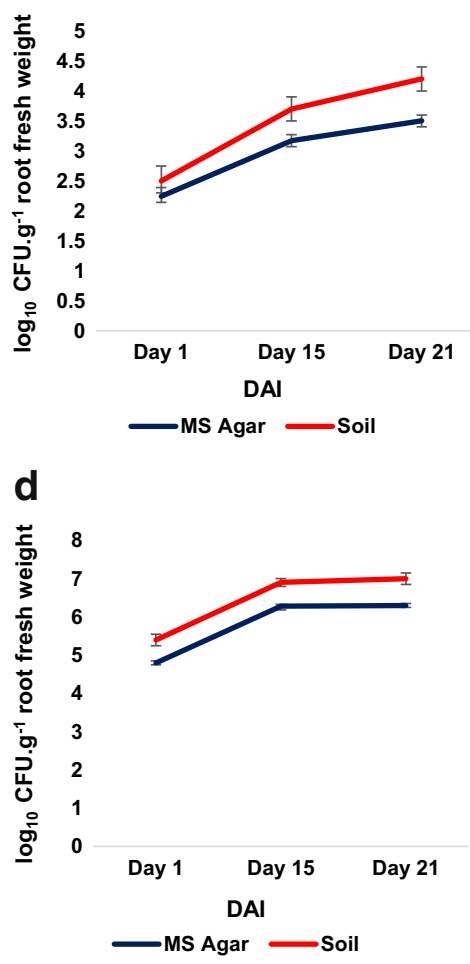

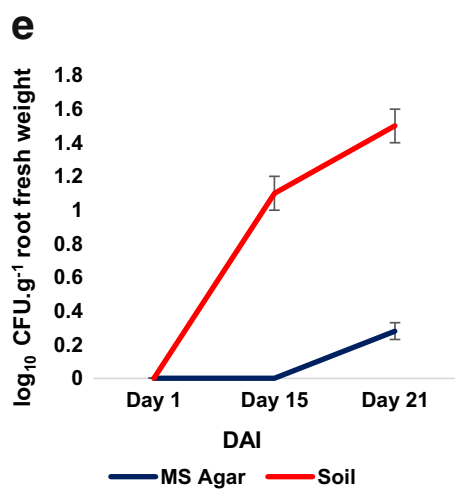

As shown in (Fig. 5), highest bacterial density was extracted from the rhizosphere of plants subject to the T3 treatment $\left(\log _{10} 8.05 \mathrm{CFU}^{-1} \mathrm{~g}^{-1}\right.$ soil) and lowest in case of T5 treatment $\left(\log _{10} 1.34\right.$ CFU.g ${ }^{-1}$ soil). Strikingly, the rhizosphere of untreated plants had comparatively a denser population than T5 treatment in soil (Fig. 5), which gradually decreased over several orders of magnitude. In contrast, the treatments T3 and T4, conditions which correlated positively with plant root growth promotion, the rhizospheric population grew steadily over time. These results clearly suggest that appropriate dose of Klebsiella SGM 81 plays important role in maintaining and increasing rhizosphere bacteria population and it may inhibit mutualistic plantrhizobacteria communities at higher titre. In control plants, the bacterial density increases gradually till 21 days, indicating that in absence of external inoculant a growing population of bacteria can be supported in the rhizosphere region as the plant ages. Overall, these findings strongly suggest that $D$. caryophyllus tolerates and perhaps nurtures bacterial populations in the rhizosphere but not when subject to very high titres of 


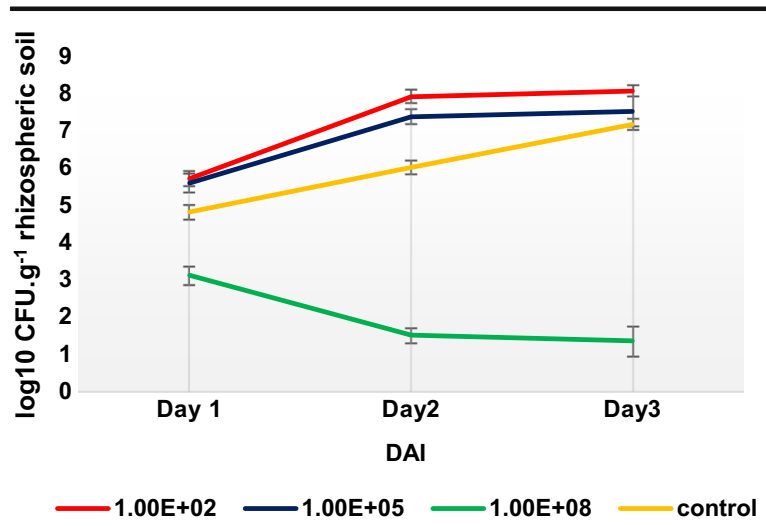

Fig. 5 Enumeration of rhizosphere bacteria. Rhizosphere bacteria densities were calculated by isolating bacteria after DAI 1, 15, 21 from soil around and adhered to plant roots treated with $10^{2}, 10^{5}$, $10^{8}$ CFU. $\mathrm{mL}^{-1}$ and control (untreated) plants . Error bars represent one SD from the mean $(\mathrm{n}=3) . P$ value $\leq 0.05$ for $10^{2}$, $10^{8}$ CFU.mL ${ }^{-1}$ vs control and $\geq 0.05$ for $10^{5}$ CFU. $\mathrm{mL}^{-1}$ vs control

Klebsiella SGM 81. We can currently not distinguish whether the decrease of rhizosphere microbial titres under treatment $\mathrm{T} 5$ is a consequence of poor plant health, in which case fewer nutrients such as sugars might be exuded into the soil, and/or whether high microbial titres may elicit plant defence mechanisms (e.g. MAMPS) that could involve the secretion of antimicrobial metabolites, which were shown to be excreted from Ocimum basilicum roots upon challenge from the pathogen Pythium ultimum (Bais et al. 2002). The observation that endophytic bacterial titres did not decline when $D$. caryophyllus when exposed to high Klebsiella SGM 81 titres but the rhizosphere titres did decline may provide some evidence that a lack of nutrient supply from a healthy plant, rather than an active plant defence accounts for the rhizosphere bacterial decline.

Klebsiella SGM 81 adheres the root epidermis and pericycle apoplast regions

Enumeration of viable bacteria of plants grown in MSagar and non-sterile soil, suggested both epiphytic and endophytic lifestyles of Klebsiella SGM 81 with D. caryophyllus. To confirm an endophytic lifestyle and better evaluate the beneficial traits of Klebsiella SGM 81, we visualised their presence on and within D. caryophyllus roots, using confocal microscopy (Fig. 6). We constructed a broad host range based vector pBBRMCS4-gfp, constitutively expressing $g f p$, which was transformed by electroporation into Klebsiella
SGM 81 for visualisation of live cells. Following root inoculation with the intermediate titre of Klebsiella SGM 81 and 7 days growth on MS-agar, roots were stained with propidium iodide. Bright field, red and green florescence images were taken to visualise roots, cell walls and Gfp-tagged bacteria, respectively. We found Klebsiella SGM 81 to be localised extensively at the rhizoplane (Fig. 6a), and also within epidermal D. caryophyllus cells (Fig. 6b, Supplementary Fig. 6a) and the root apoplast (Fig. 6c, Supplementary Fig. 6b). We did not detect any green fluorescent bacteria in or on non-inoculated roots (Fig. 6d, Supplementary Fig. 6c). We conclude that Klebsiella SGM 81 is an excellent rhizoplane coloniser and also endophyte of D. caryophyllus.

Klebsiella SGM 81 genome sequencing and phylogeny

We carried out a 16S RNA phylogenetic analysis and phylogenetic tree was produced based on the $16 \mathrm{~S}$ sequence of accession KU748780 at various scales. It was identified as Klebsiella quasipneumonae based on sequence homology (Fig. 7). The percent homology of Klebsiella SGM 81 to other nearest Klebsiella quasipneumoniae_01A030 is 94\% and that with Klebsiella quasipneumoniae_07A044 is $93.7 \%$. We determined the whole genome sequence of Klebsiella SGM 81 and complete genome sequence have been submitted (accession number PRJEB21197) to the European Bioinformatics Institute (EMBL-EBI). Details are provided in the "Materials and methods" section and supplementary table. We inspected the Klebsiella SGM 81 genome for the presence of rmpA and rmpA2 genes, coding for capsule formation and indicative for Klebsiella pneumonia type 1 strains that are most frequently associated with human infections. The absence of these genes in Klebsiella SGM 81 genome suggests limited pathogenicity potential (Holt et al. 2015).

\section{Discussion}

Bacteria of the genus Klebsiella have been found to associate with roots of several agriculturally important crops, in some cases endophytically, and have been shown to promote plant growth via auxin production (El-Khawas and Adachi 1999) and nitrogen fixation (Gyaneshwar et al. 2001). Here we show that Klebsiella SGM 81, endogenous to the rhizosphere of 

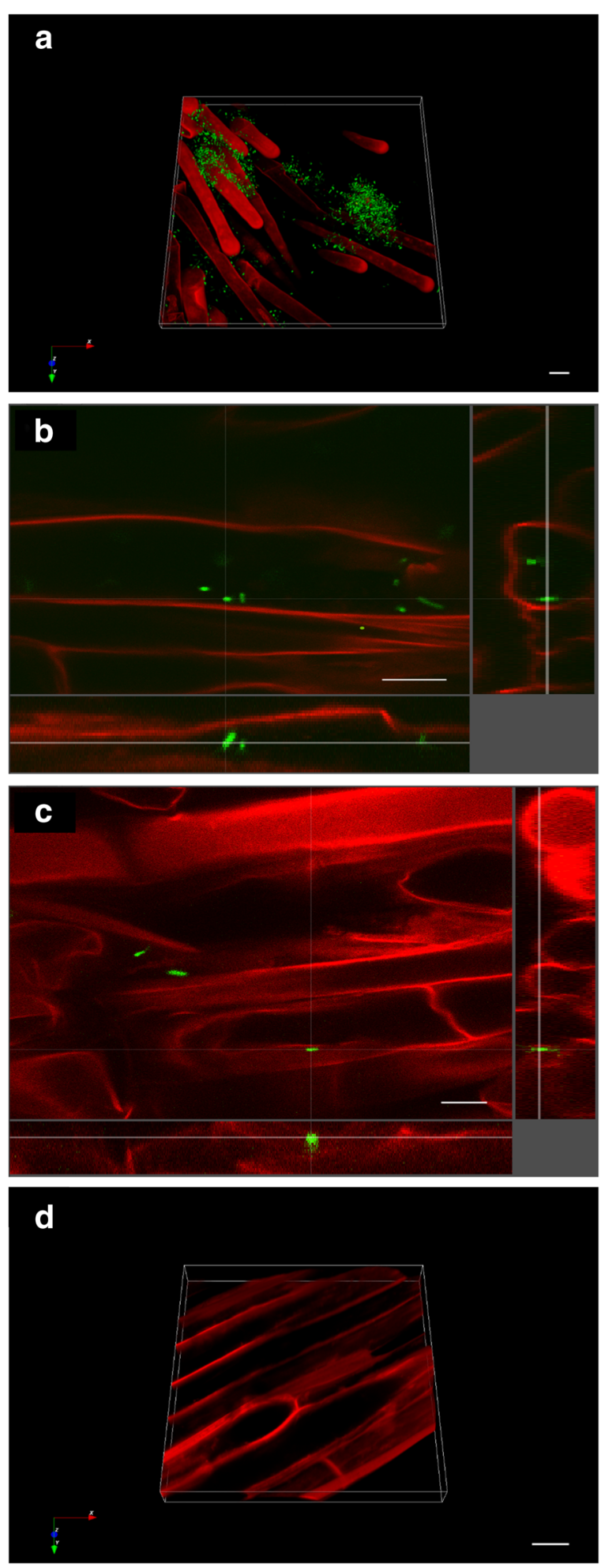

Fig. 6 Microscopy of root tissue to localise $g f p$ tagged Klebsiella SGM 81. Colonisation of Carnation roots by $g f p$ tagged Klebsiella SGM 81. Confocal microscopy was performed using $1 \mathrm{~cm}$ long root section. Images showing 3D rhizoplane (a), within epidermal D. caryophyllus cells (b), the root apoplasm (c) and non-treated control root cells and rhizoplane (d). Cross hair analysis of 3D images (Fig. 6b and c) indicate that SGM 81 localises rhizoplane and apoplast respectively. Scale bar: $10 \mu \mathrm{m}$

D. caryophyllus, strongly promotes its host's root development in the first weeks of plant growth. The primary root length $(\mathrm{cm})$ of plants treated with synthetic IAA and bacterial IAA is nearly $23 \%$ longer than the primary root length of untreated plants. Plants treated with $10^{5}$ CFU.mL ${ }^{-1}$ of bacteria grown in soil yielded $125 \%, 232 \%, 663 \%, 347 \%$ greater outcomes than control plants for primary root length, number of lateral roots, number of root hairs and dry root weight, respectively. Several fold increases in plant root attributes when inoculated with plant growth promoting rhizobacteria have been reported, for example for Streptomyces on rice (Harikrishnan et al. 2014) and Kocuria turfanensis on groundnut (Goswami et al. 2014). It was previously unclear if these root morphological changes are a general or a specific feature of beneficial Klebsiella-plant systems, however, our similar findings with both $D$. caryophyllus and A. thaliana may suggest the former. Plant growth promoting phenotypes with both endogenous and exogenous Klebsiella species have been reported, for instance, the enhancement of wheat growth during abiotic stress (Singh et al. 2015), the capacity for nitrogen fixation in wheat (Riggs et al. 2002) and the enhancement growth of Salicornia bigelovii by (Rueda-Puente et al. 2003). However, it remains generally challenging to attribute specific bacterial plant growth promoting properties or combinations thereof e.g. phosphate solubilisation, IAA production, nitrogen fixation and ACC deaminase production to plant growth phenotypes, due to the complexities of the rhizosphere ecology (Saharan and Nehra 2011). Our plant growth promotion phenotypes, which were assayed under controlled agarose plate conditions in addition to soil in order to minimise such complexity, we propose that IAA is a major contributing factor to the stimulation of root development on D. caryophyllus. Importantly, the Murashige Skoog growth media used comprised high concentrations of soluble phosphate 
Fig. 7 Phylogenetic tree of Klebsiella SGM 81 based on aligned 16 s rRNA sequences. The subject strain is highlighted in red colour. The tree was produced using 10,000 bootstrap iterations. The numbers are the bootstra $p$ values giving an idea of the confidence in the placement of the taxa. The nearest member strain of Klebsiella SGM 81 is Klebsiella quasipneumonae

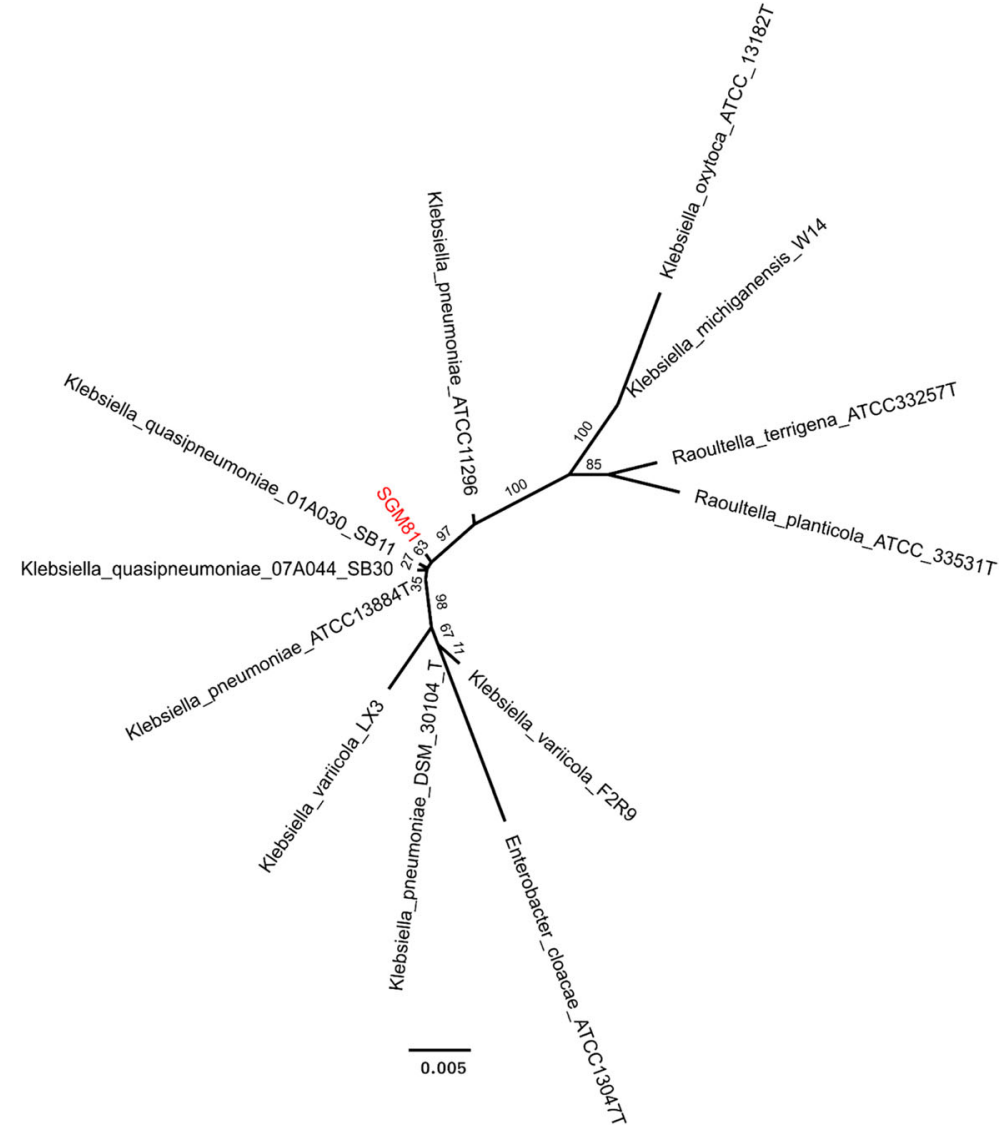

$(12.5 \mathrm{mM})$ and nitrogen source $(20 \mathrm{mM})$. Since nif gene expression (coding inter alia for the nitrogenase enzyme) and GDH/Pqq enzyme activity are stringently regulated and their induction requires no, or extremely low, nitrogen source (Dixon and Kahn 2004) and phosphate in the environment (Goldstein and Liu 1987), respectively, it is highly unlikely that these attributes account for the plant phenotypic outcomes in our experiments. Further, we inspected the SGM 81 genome and found no candidate $a c d S$ gene, required in other PGPR for ACC deaminase activity, excluding this PGP trait as a likely factor for our observations. We provided further evidence of IAA production by Klebsiella SGM 81 to account for the promotion of root growth, given the very similar root growth patterns of D. caryophyllus supplemented with commercial IAA or when inoculated with Klebsiella SGM 81 and evidencing tryptophan dependent IAA production proximal to root hairs in situ.
High density inoculum $\left(10^{8} \mathrm{CFU} \cdot \mathrm{mL}^{-1}\right)$ exhibited negative effect on plant root development whether grown in soil or on MS Agar. A number of reasons could account for this, for example: (i) higher inoculation might lead to more IAA production, which would induce ethylene production and thus inhibit root growth and development (Husen et al. 2009); (ii) high density inocula could produce plant growth harmful metabolites inhibiting root development as shown in Convolvulus arvensis L (Sarwar and Kremer 1995); or (iii) high microbial titres may elicit plant defence mechanisms such as microbial associated molecular patterns (MAMPS) with adverse plant growth effects (Doornbos et al. 2012). However, because the high density Klebsiella SGM 81 inoculum resulted in poorer health of $D$. caryophyllus that correlated with a rapid decline in the rhizospheric bacterial population but not in a decline of endophytic bacteria, we propose that whatever the cause of poor plant health, the decline of rhizophere bacterial population is mainly 
attributable to a lack of positive effects of the plant towards bacteria, rather than a plant defence mechanism that would also target endophytic bacteria. This rational would be congruent with a strong mutualistic relationship between $D$. caryophyllus and rhizopheric bacteria, and specifically Klebsiella SGM 81.

We showed the presence of an ipdC gene in Klebsiella SGM 81 and demonstrated the production of substantial amounts of IAA in batch cultures supplemented with tryptophan. ipdC has been isolated and characterized from Azospirillum brasilense by (Costacurta et al. 1994), Pseudomonas putida by (Patten and Glick 2002b) and others and is generally associated with tryptophan dependent IAA production, fully consistent with our findings that IAA production was strictly dependent on tryptophan as substrate in batch cultures. It is worth noting that we found Klebsiella SGM 81 to produce substantially higher IAA amounts $\left(190 \mu \mathrm{g} \cdot \mathrm{mL}^{-1}\right)$ compared with another Klebsiella strain (22.7 mg. $\mathrm{L}^{-1}$ ) studied by Sachdev et al. (2009), provided with the same concentration of tryptophan $(0.1 \%)$. Interestingly, the IAA yields of Klebsiella SGM 81 observed in batch cultures are comparable with those reported for Klebsiella pnb8 (869 $\left.\mu \mathrm{g} \cdot \mathrm{mL}^{-1}\right)$ after addition of plant extract instead of tryptophan (Jasim et al. 2013). While tryptophan is commonly found in plant root exudates (Kravchenko et al. 2004), we did not directly determine tryptophan concentrations in D. caryophyllus exudates, which cannot be readily estimated in our experimental set up. The impact of the externally provided auxin IAA on root development is diverse and the production of IAA in plants complicates our understanding of IAA, which controls important plant developmental processes, such as tissue differentiation, cell enlargement and division (Teale et al. 2006). Externally applied IAA - either via direct IAA application or indirectly via IAA producing microbes, can have both plant growth promoting and plant deleterious effects and various microbial metabolic pathways to produce IAA have been associated with positive and negative plant outcomes (Spaepen and Vanderleyden 2011). We found that IAA, either applied directly or via inoculation with Klebsiella SGM 81 to have a generally positive effect on root growth of D. caryophyllus, apart from when applying very high titres of Klebsiella SGM 81 that are unlikely to occur in soil. This interpretation is consistent with the notion that most beneficial bacteria produce IAA via the so called indole-3-pyruvate pathway, for which ipdC is indicative, and which is thought to also be the most widespread IAA biosynthesis pathway in bacteria. We also found that a healthy $D$. caryophyllus correlated with the proliferation of the soil microbial community and specifically Klebsiella SGM 81 in the absence of other bacteria (MS-agarose). Taken together, our results strongly suggest that Klebsiella SGM 81 and D. caryophyllus have evolved a strong mutualistic relationship where IAA production by the former is likely to be a key determinant in this relationship.

We also showed that Klebsiella SGM 81 is an endophytic root coloniser of the $D$. caryophyllus apoplast. In support of this, K. pneumoniae has been reported to colonise the interior of maize roots and stems, with bacteria seen on the epidermis layer and pericycle region of the root, followed by relatively lower number of bacteria in the apoplast. (Chelius and Triplett 2000). Another report demonstrated a Klebsiella strain was able to colonise pepper roots, with cells on root hairs and lateral roots compared to the rhizoplane (Marasco et al. 2012). Our finding that the vast majority of Klebsiella SGM 81 appear to colonise the D. caryophyllus root and root hairs may suggest that IAA production and the resulting promotion of root and root hair growth could act locally through Klebsiella SGM 81 colonising the rhizoplane. Interestingly, exudation of plant derived tryptophan has been localised mainly near secondary graminacious root (Vacheron et al. 2013), so that tryptophan dependent bacterial IAA production could represent a beneficial biochemical 'outsourcing'.

Our study focuses on mutualism between Klebsiella SGM 81 and D. caryophyllus and effect of IAA produced by SGM 81 on root architecture of plant. The exogenous IAA available to the plant roots exhibits the growth promotion of roots. We however could not validate if inoculation with SGM 81 along with its IAA triggers endogenous auxin synthesis by D. caryophyllus and together accounts for the change in root architecture, which constitutes future research study. Furthermore, the study of response of plant to the bacterial IAA at molecular levels will be valuable to understand the auxin induced plant microbial interactions.

Acknowledgements At Imperial College London, we thank Mark Bennett for the LC-MS/MS analysis, James Abbott for the genome assembly and phylogenetic analysis and David C.A. Gaboriau from FILM facility for support with confocal microscopy and are grateful to Professor Martin Buck to enable us carry out experiments in his laboratory. We are thankful to Department of Science and Technology, India for the financial assistance under INSPIRE Fellowship 2014-15 (IF 140042). This work was also supported the BBSRC (BBSRC GCRF IAA grant and BB/003608/1), UK. 
Open Access This article is distributed under the terms of the Creative Commons Attribution 4.0 International License (http:// creativecommons.org/licenses/by/4.0/), which permits unrestricted use, distribution, and reproduction in any medium, provided you give appropriate credit to the original author(s) and the source, provide a link to the Creative Commons license, and indicate if changes were made.

\section{References}

Ahemad M, Khan MS (2011) Effects of insecticides on plantgrowth-promoting activities of phosphate solubilizing rhizobacterium Klebsiella sp. strain PS19. Pestic Biochem Physiol 100:51-56

Ali B, Sabri A, Ljung K, Hasnain S (2009) Auxin production by plant associated bacteria: impact on endogenous IAA content and growth of Triticum aestivum L. Lett Appl Microbiol 48: 542-547

Bais HP, Walker TS, Schweizer HP, Vivanco JM (2002) Root specific elicitation and antimicrobial activity of rosmarinic acid in hairy root cultures of Ocimum basilicum. Plant Physiol Biochem 40:983-995

Bent A (2006) Arabidopsis thaliana floral dip transformation method. Agrobacterium Protoc:87-104

Bhardwaj D, Ansari MW, Sahoo RK, Tuteja N (2014) Biofertilizers function as key player in sustainable agriculture by improving soil fertility, plant tolerance and crop productivity. Microb Cell Factories 13:66

Bhattacharyya P, Jha D (2012) Plant growth-promoting rhizobacteria (PGPR): emergence in agriculture. World J Microbiol Biotechnol 28:1327-1350

Camacho C, Coulouris G, Avagyan V et al (2009) BLAST+: architecture and applications. BMC Bioinf 10:421

Chandra S, Rawat D, Chandra D, Rastogi J (2016) Nativity, phytochemistry, ethnobotany and pharmacology of dianthus caryophyllus. Res J Med Plant 10:1-9

Chelius MK, Triplett EW (2000) Immunolocalization of dinitrogenase reductase produced by Klebsiella pneumoniae in Association with Zea mays L. Appl Environ Microbiol 66: 783-787

Cole JR, Chai B, Farris RJ et al (2005) The ribosomal database project (RDP-II): sequences and tools for high-throughput rRNA analysis. Nucleic Acids Res 33:D294-D296

Cormack BP, Valdivia RH, Falkow S (1996) FACS-optimized mutants of the green fluorescent protein (GFP). Gene 173: 33-38

Costacurta A, Keijers V, Vanderleyden J (1994) Molecular cloning and sequence analysis of an Azospirilium brasilense indole3-pyruvate decarboxylase gene. Mol Gen Genet MGG 243: 463-472

Criscuolo A, Gribaldo S (2010) BMGE (block mapping and gathering with entropy): a new software for selection of phylogenetic informative regions from multiple sequence alignments. BMC Evol Biol 10:210

Darling AE, Mau B, Perna NT (2010) ProgressiveMauve: multiple genome alignment with gene gain, loss and rearrangement. PloS One 5:e11147
Datsenko KA, Wanner BL (2000) One-step inactivation of chromosomal genes in Escherichia coli K-12 using PCR products. Proc Natl Acad Sci 97:6640-6645

de Chaumont F, Dallongeville S, Provoost T, et al (2013) Icy: a user-friendly environment for algorithm development and deployment. IEEE, pp 1-5

de Souza R, Ambrosini A, Passaglia LM (2015) Plant growthpromoting bacteria as inoculants in agricultural soils. Genet Mol Biol 38:401-419

Dixon R, Kahn D (2004) Genetic regulation of biological nitrogen fixation. Nat Rev Microbiol 2:621

Dobbelaere S, Croonenborghs A, Thys A et al (1999) Phytostimulatory effect of Azospirillum brasilense wild type and mutant strains altered in IAA production on wheat. Plant Soil 212:153-162

Doornbos RF, van Loon LC, Bakker PA (2012) Impact of root exudates and plant defense signaling on bacterial communities in the rhizosphere. A review. Agron Sustain Dev 32:227-243

Edgar RC (2004) MUSCLE: multiple sequence alignment with high accuracy and high throughput. Nucleic Acids Res 32: 1792-1797

El-Khawas H, Adachi K (1999) Identification and quantification of auxins in culture media of Azospirillum and Klebsiella and their effect on rice roots. Biol Fertil Soils 28:377-381

Fournet-Fayard S, Joly B, Forestier C (1995) Transformation of wild type Klebsiella pneumoniae with plasmid DNA by electroporation. J Microbiol Methods 24:49-54

Goldstein A, Liu S (1987) Molecular cloning and regulation of a mineral phosphate solubilizing gene from Erwinia herbicola. Nat Biotechnol 5:72-74

Goswami D, Pithwa S, Dhandhukia P, Thakker JN (2014) Delineating Kocuria turfanensis $2 \mathrm{M} 4$ as a credible PGPR: a novel IAA-producing bacteria isolated from saline desert. J Plant Interact 9:566-576 https://doi. org/10.1080/17429145.2013.871650

Gravel V, Antoun H, Tweddell RJ (2007) Growth stimulation and fruit yield improvement of greenhouse tomato plants by inoculation with Pseudomonas putida or Trichoderma atroviride: possible role of indole acetic acid (IAA). Soil Biol Biochem 39:1968-1977

Grossman JD, Rice KJ (2012) Evolution of root plasticity responses to variation in soil nutrient distribution and concentration: Barley root plasticity. Evol Appl 5:850-857 https://doi.org/10.1111/j.1752-4571.2012.00263.x

Gyaneshwar P, James EK, Mathan N et al (2001) Endophytic colonization of rice by a diazotrophic strain of Serratia marcescens. J Bacteriol 183:2634-2645

Harikrishnan H, Shanmugaiah V, Balasubramanian N (2014) Optimization for production of Indole acetic acid (IAA) by plant growth promoting Streptomyces sp VSMGT1014 isolated from rice rhizosphere. Int J Curr Microbiol Appl Sci 3:158-171

Hayat R, Ali S, Amara U et al (2010) Soil beneficial bacteria and their role in plant growth promotion: a review. Ann Microbiol 60:579-598

Holt KE, Wertheim H, Zadoks RN et al (2015) Genomic analysis of diversity, population structure, virulence, and antimicrobial resistance in Klebsiella pneumoniae, an urgent threat to public health. Proc Natl Acad Sci 112:E3574-E3581

Husen E, Wahyudi AT, Suwanto A et al (2009) Soybean seedling root growth promotion by 1-aminocyclopropane-1- 
carboxylate deaminase-producing pseudomonads. Indones J Agric Sci 10:19-25

Jasim B, Jimtha CJ, Jyothis M, Radhakrishnan E (2013) Plant growth promoting potential of endophytic bacteria isolated from Piper nigrum. Plant Growth Regul 71:1-11

Jha CK, Saraf M (2011) In vitro evaluation of indigenous plant growth promoting rhizobacteria isolated from Jatropha curcas rhizosphere. Int J Genet Eng Biotechnol 2:91-100

Jha CK, Patel D, Rajendran N, Saraf M (2010) Combinatorial assessment on dominance and informative diversity of PGPR from rhizosphere of Jatropha curcas L. J Basic Microbiol 50: 211-217

Jha CK, Annapurna K, Saraf M (2012) Isolation of Rhizobacteria from Jatropha curcas and characterization of produced ACC deaminase. J Basic Microbiol 52:285-295

Karnwal A (2009) Production of indole acetic acid by fluorescent Pseudomonas in the presence of L-tryptophan and rice root exudates. J Plant Pathol:61-63

Kovach M, Phillips R, Elzer P et al (1994) pBBR1MCS: a broadhost-range cloning vector. BioTechniques 16:800-802

Kravchenko L, Azarova T, Makarova N, Tikhonovich I (2004) The effect of tryptophan present in plant root exudates on the phytostimulating activity of rhizobacteria. Microbiology 73 : $156-158$

Mahl M, Wilson P, Fife M, Ewing W (1965) Nitrogen fixation by members of the tribe Klebsielleae. J Bacteriol 89:1482-1487

Marasco R, Rolli E, Ettoumi B et al (2012) A drought resistancepromoting microbiome is selected by root system under desert farming. PLoS One 7:e48479 https://doi.org/10.1371 /journal.pone.0048479

Mastretta C, Taghavi S, Van Der Lelie D et al (2009) Endophytic bacteria from seeds of Nicotiana tabacum can reduce cadmium phytotoxicity. Int J Phytoremediation 11:251-267

Mayak S, Tirosh T, Glick B (1999) Effect of wild-type and mutant plant growth-promoting rhizobacteria on the rooting of mung bean cuttings. J Plant Growth Regul 18:49-53

Meuwly P, Pilet P-E (1991) Local treatment with indole-3-acetic acid induces differential growth responses in Zea mays L. roots. Planta 185:58-64

Patten CL, Glick BR (1996) Bacterial biosynthesis of indole-3acetic acid. Can J Microbiol 42:207-220

Patten CL, Glick BR (2002a) Role of pseudomonas putida indoleacetic acid in development of the host plant root system. Appl Environ Microbiol 68:3795-3801

Patten CL, Glick BR (2002b) Regulation of indoleacetic acid production in pseudomonas putida GR12-2 by tryptophan and the stationary-phase sigma factor RpoS. Can J Microbiol 48:635-642

Peck SC, Kende H (1995) Sequential induction of the ethylene biosynthetic enzymes by indole-3-acetic acid in etiolated peas. Plant Mol Biol 28:293-301

Persello-Cartieaux F, Nussaume L, Robaglia C (2003) Tales from the underground: molecular. Plant Cell Environ 26:189-199

Riggs P, Moritz R, Chelius M et al (2002) Isolation and characterization of diazotrophic endophytes from grasses and their effects on plant growth. Nitrogen Fixat Glob Perspect N Y NY CAB Int:263-267

Rueda-Puente E, Castellanos T, Troyo-Diéguez E et al (2003) Effects of a nitrogen-fixing indigenous bacterium
(Klebsiella pneumoniae) on the growth and development of the halophyte salicornia bigelovii as a new crop for saline environments. J Agron Crop Sci 189:323-332

Sachdev DP, Chaudhari HG, Kasture VM, et al (2009) Isolation and characterization of indole acetic acid (IAA) producing Klebsiella pneumoniae strains from rhizosphere of wheat (Triticum aestivum) and their effect on plant growth

Saharan B, Nehra V (2011) Plant growth promoting rhizobacteria: a critical review. Life Sci Med Res 21:30

Sarwar M, Kremer RJ (1995) Enhanced suppression of plant growth through production of L-tryptophan-derived compounds by deleterious rhizobacteria. Plant Soil 172:261-269

Seemann T (2014) Prokka: rapid prokaryotic genome annotation. Bioinformatics btu153

Shanan NT, Higazy AM (2009) Integrated biofertilization management and cyanobacteria application to improve growth and flower quality of Matthiola incana. Res J Agric Biol Sci $5: 1162$

Shiragur M, Shirol A, Reddy B, Kulkarni B (2004) Performance of standard carnation (Dianthus caryophyllus L.) cultivars under protected cultivation for vegetative characters. J Ornam Hortic 7:212-216

Singh RP, Jha P, Jha PN (2015) The plant-growth-promoting bacterium Klebsiella sp. SBP-8 confers induced systemic tolerance in wheat (Triticum aestivum) under salt stress. J Plant Physiol 184:57-67 https://doi.org/10.1016/j. jplph.2015.07.002

Spaepen S, Vanderleyden J (2011) Auxin and plant-microbe interactions. Cold Spring Harb Perspect Biol 3:a001438

Stamatakis A (2014) RAxML version 8: a tool for phylogenetic analysis and post-analysis of large phylogenies. Bioinformatics 30:1312-1313

Teale WD, Paponov IA, Palme K (2006) Auxin in action: signalling, transport and the control of plant growth and development. Nat Rev Mol Cell Biol 7:847-859

Timmusk S, Grantcharova N, Wagner EGH (2005) Paenibacillus polymyxa Invades Plant Roots and Forms Biofilms. Appl Environ Microbiol 71:7292-7300 https://doi.org/10.1128 /AEM.71.11.7292-7300.2005

Tsavkelova EA, Cherdyntseva TA, Botina SG, Netrusov AI (2007) Bacteria associated with orchid roots and microbial production of auxin. Microbiol Res 162:69-76 https://doi.org/10.1016/j.micres.2006.07.014

Vacheron J, Desbrosses G, Bouffaud M-L et al (2013) Plant growth-promoting rhizobacteria and root system functioning. Front Plant Sci 4:356

Walker BJ, Abeel T, Shea T et al (2014) Pilon: an integrated tool for comprehensive microbial variant detection and genome assembly improvement. PLoS One 9:e112963

Weller DM, Raaijmakers JM, Gardener BBM, Thomashow LS (2002) Microbial populations responsible for specific soil suppressiveness to plant pathogens 1. Annu Rev Phytopathol 40:309-348

Wu Z, Peng Y, Guo L, Li C (2014) Root colonization of encapsulated Klebsiella oxytoca Rs-5 on cotton plants and its promoting growth performance under salinity stress. Eur J Soil Biol 60:81-87

Zulfitri A (2012) Plant growth promotion by IAA-producing rhizobacteria in ornamental plant propagation 